\title{
In Memory of Ray Kunze
}

\author{
Kenneth I. Gross and Edward N. Wilson
}

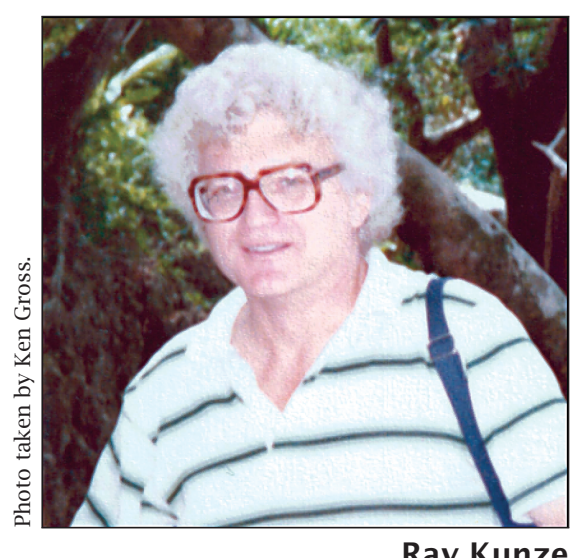

Ray Alden Kunze passed away on May 21, 2014, after a lengthy illness. Ray was a longtime member of the AMS, served on the AMS Council and a number of American Mathematical Society committees, and was selected as an Inaugural Fellow in 2012. He published over fifty research articles, among which were sem-

Ray Kunze inal results of primary importance in representation theory and harmonic analysis. As well, his classic textbook on linear algebra, co-authored with Kenneth Hoffman, was translated into many languages and used around the world.

Ray was born March 7, 1928, in Des Moines, Iowa, but lived much of his youth in the area around Milwaukee, Wisconsin. He received his bachelor of science and master of science degrees in mathematics from the University of Chicago. A talented tennis player, he was captain of the University of Chicago tennis team. He played competitive tennis and then table tennis all of his life. His graduate studies were interrupted during the early 1950s by military service, during which period he served as a mathematical analyst in the Department of Defense. Upon completion of his tour of duty he returned to his doctoral studies at the University of Chicago and in 1957 received his doctor of philosophy degree in mathematics.

Ray began his mathematics career on the faculty of MIT and over the ensuing years served on

Kenneth I. Gross is professor of mathematics at the University of Vermont. His email address is kgross@uvm. edu.

Edward N. Wilson is professor of mathematics at Washington University. His email address is enwi 1 son@math.wust 1 . edu.

For permission to reprint this article, please contact:

reprint-permission@ams .org.

DOI: http://dx.doi.org/10.1090/noti1283 the faculties of Brandeis University, Washington University, the University of California at Irvine, and the University of Georgia. At both Irvine and Georgia he chaired the Department of Mathematics. He also held numerous visiting positions in the United States, including the Institute for Advanced Study at Princeton, and in England, Belgium, France, Italy, Germany, Australia, and Taiwan.

Three aspects of Ray's research can be singled out as especially notable: (i) His joint work with Eli Stein in the late 1950s and 1960s ("the KunzeStein phenomena") in which they constructed uniformly bounded nonunitary representations of a semisimple Lie group $G$ and showed that convolution by an $L^{p}$ function is a bounded operator on $L^{2}(G)$ for all $1 \leq p<2$. There is no analogue in the classical theory, as convolution by an $L^{p}$ function on $R^{n}$ is bounded only when $p=1$. (ii) His papers on noncommutative $L^{p}$ spaces associated with a von Neumann algebra, a topic initiated by Irving Segal and Jacques Dixmier in the 1950s and which is now a wellestablished area with hundreds of contributors. (iii) His joint work in the 1970s and 1980s with Ken Gross on operator-valued Bessel functions ("GrossKunze Bessel functions") and their application to noncommutative harmonic analysis and to the infinite-dimensional representation theory of semisimple Lie groups.

Ray was also an inspirational teacher who advised eleven doctoral students, a number of whom have gone on to distinguished careers and three of whom are Fellows of the AMS. Those who had the great privilege of being his student received the best possible mathematical training. 